\title{
DEPTH-AVERAGED FLOW FIELDS IN MEANDERING \\ CHANNELS WITH ALLUVIAL EQUILIBRIUM BED
}

Nobuyuki Tamai, Professor

Ali A. Mohamed, Graduate Student

\section{INTRODUCTION}

University of Tokyo

A characteristic feature of the mechanics of alluvial channels is that the bed is self-formed by the interaction of flow and sediment motion. In this paper a mathematical analysis of the longitudinal variation of the depth-averaged flow in continuous river bends with alluvial equilibium bed is developed. A new experssion for the bed topography is applied apart from an exponential function utilized by Engelund (1). The solution is obtained up to the second order in terms of $\varepsilon$ by a perturbation method. The results are compared with existing experimental data.

\section{THEORY}

\subsection{Coordinate System and Governing Equations}

The theoretical solution is derived for meandering channels the centerline of which coincide with the sine-generated curve.

$$
\theta=\theta_{0} \sin \frac{2 \pi s c}{L}
$$

where $\theta=$ the angle between the tangent of the channel centerline and the down-valley direction at a distance $s$ from the origin measured along the channel centerline, $\theta=$ the maximum angle between the centerline and the valley axis, $L=$ the meandering length of one meander along the centerline and $S_{C}=$ the distance along the centerline of the channel (see Fig. 1).

In this theory, it is utilized the three dimensional coordinate system $\left(s_{a}, n_{a}, z_{a}\right)$ in which $\left(s_{a}, n_{a}\right)$ composes an orthogonal curvilinear coordinate ${ }_{\text {s }}$ stem (3). The $\mathrm{n}^{\mathrm{a}}$-coordinate is the transverse distance measured from the centerline and perpendicular to $s$ on the same plane

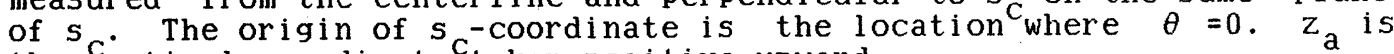
the vertical coordinate ${ }^{c}$ taken positive upward.

The main assumptions in the governing equations utilized in this theory are explained in previous paper( 3 ). In this paper, it is assumed that the longitudinal component of the bed shear stress is sufficiently close to the total bed shear.

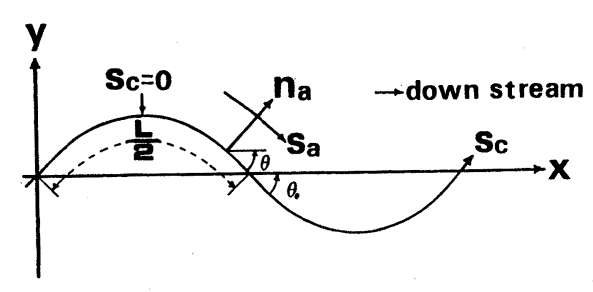

Fig. 1 Coordinate system

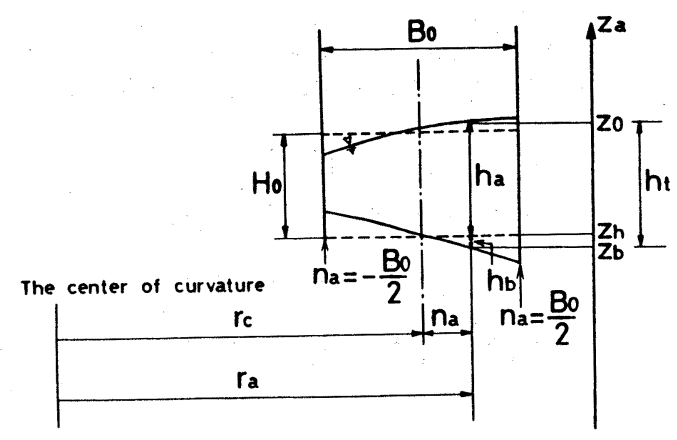

Fig. 2 Cross section of the channel and symbols 


$$
\frac{\tau_{\mathrm{o}}}{\rho}=\frac{1}{2} \mathrm{f}\left(\mathrm{u}_{\mathrm{s}}\right)^{2}
$$

where $f$ is the friction coefficient.

For convenience let us begin with the nondimensional form of the governing equtions ( 3 ).

$$
\begin{aligned}
& \varepsilon \frac{\partial}{\partial s}[(h+\eta) u]+\frac{\partial}{\partial n}\left[\frac{r_{a}}{r_{c}}(h+\eta) v\right]=0 \\
& \frac{1}{2} \int_{-1}^{1}(h+\eta) u d n=1 \\
& u \frac{\partial u}{\partial s}+\frac{r_{a}}{r_{c}} \frac{1}{\varepsilon} v \frac{\partial u}{\partial n}+\frac{R}{r_{c}} u v=\frac{1}{F_{r}^{2}} \frac{\partial h}{\partial s}+\frac{g i R}{v^{2}}-\frac{c}{2} \frac{r_{a}}{r_{c}} \frac{u^{2}}{h+\eta} \\
& \frac{r_{c}}{r_{a} u \frac{\partial v}{\partial s}}+v \frac{\partial v}{\partial n}-\frac{n_{0}}{r_{a}} u^{2}=\frac{1}{F_{r}^{2}} \frac{\partial h}{\partial n}
\end{aligned}
$$

where Eq. 3 is the continuity equation, Eq.4 the sectional discharge and Eqs. 5\& 6 the momentum equations in $s$ and $n_{a}$ directions, respectavely.

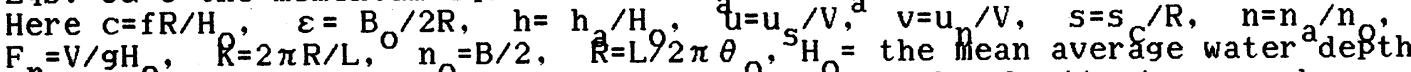

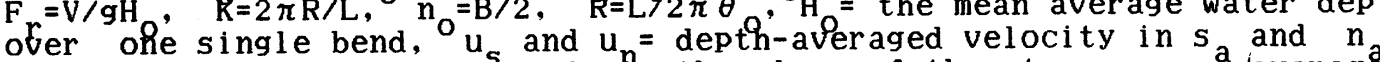
directions, respectively ${ }^{s}$ and $p=$ the slope of the transverse average level of the bed. The main symbols in this paper are illustrated in Fig. 2 .

The boundary conditions are nondimensionalized as follows ( 3 ):

$$
\begin{aligned}
& v=0 \quad \text { at } n= \pm 1 \\
& u=u_{i}(n) \quad \text { at } s=s_{0} \text { (upstream end) } \\
& \frac{1}{2} \int_{-1}^{1} h \mathrm{dn}=1 \text { at } s=s_{d} \text { (downstream end) }
\end{aligned}
$$

\subsection{Solutions by the Perturbation Method}

In present analysis the perturbation method is used in terms of $\varepsilon$ to solve the governing equations. The peturbed expression for the hydraulic quantities are presented as follows:

$$
\begin{aligned}
h & =h_{0}+\varepsilon h_{1}+\varepsilon{ }^{2} h_{2}+\ldots \ldots \ldots \\
u & =u_{0}+\varepsilon u_{1}+\varepsilon{ }^{2} u_{2}+\ldots \ldots \ldots \\
v & =v_{0}+\varepsilon v_{1}+\varepsilon \varepsilon^{2} v_{2}+\ldots \ldots \ldots \\
u_{i} & =u_{i o}+\varepsilon u_{i 1}+\varepsilon^{2}\left(n^{2}-\frac{1}{3}\right) u_{i 2}+\ldots \ldots \ldots \\
\eta & =\eta_{0}+\varepsilon \eta_{1}+\varepsilon \eta_{2}+\ldots \ldots \ldots \\
& =\varepsilon n\left(a_{0} \operatorname{sinks}+a_{1} \cos k s\right)+\varepsilon^{2}\left(n^{2}-\frac{1}{3}\right)\left(a_{2}+a_{3} \sin 2 k s+a_{4} \cos 2 k s\right)
\end{aligned}
$$


where $u_{i j}, u_{j 1}$ and $u_{j}$ in the fourth equation of Eq. 5 are constants (3). The fifth equation of Eq. 5 is an equation which determines the equilibrium bed profile and it is found to be a quadratic equation with

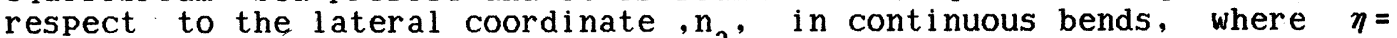
$\left(H_{0}-h\right) / H_{0}$ and $a_{0}, a_{1}, a_{2}, a_{3}$ and $a_{4}$ are constants. It is assumed that the flow is in quasi-aniform. The derfvation of the solution follows the line described in the preceding paper (3).

2.2.1 Zeroth Order Solutions

The zeroth order solutions from equilibrium bed are the same in case of rectangular channel $\left(\eta_{0}=0\right)$. The solutions are shown as follows:

$$
\begin{aligned}
& v_{0}=0 \\
& h_{0}=1 \\
& u_{0}=1 \\
& v=(2 g i R / c) 1 / 2
\end{aligned}
$$

where the fourth relation in Eq. 9 shows the condition of the normal flow.

\subsubsection{First Order Solutions}

The nondimensional expressions for the first order solition are found out as follows:

$$
\begin{aligned}
& \mathrm{h}=\mathrm{h}_{\mathrm{o}}+\varepsilon \mathrm{h}_{1}=1+\varepsilon \mathrm{nF}_{\mathrm{r}}^{2} \cos \mathrm{ks} \\
& \mathrm{u}=\mathrm{u}_{\mathrm{o}}+\varepsilon \mathrm{u}_{1}=1+\varepsilon \mathrm{n}\left(\mathrm{A} \sin \mathrm{ks}+\mathrm{B} \cos \mathrm{ks}+\mathrm{C}_{3} \mathrm{e}^{-\mathrm{cs}}\right) \\
& \mathrm{v}=\mathrm{v}_{\mathrm{o}}+\mathrm{v}_{1}=0
\end{aligned}
$$

where

$$
\begin{aligned}
& A=\frac{k c}{2\left(k^{2}+c^{2}\right)}\left(1+F_{r}^{2}+a_{1}\right)+\frac{a_{o} c^{2}}{2(k 2+c 2)} \\
& \left.B=\frac{1}{k^{2}+c^{2}}{ }^{c^{2}}\left(F_{r}^{2}-1+a_{1}\right)-k^{2}-\frac{c k}{2} a_{o}\right] \\
& C_{3}=\left(u_{i 1}-A \sin k s_{o}-B \cos k s_{o}\right) e^{c s}
\end{aligned}
$$

\subsubsection{Second Order Solutions}

The nondimensional expression of the second order solution are obtained as follows:

$\mathrm{h}_{2}(\mathrm{~s}, \mathrm{n})=\mathrm{h}_{21}+\mathrm{h}_{22}$

$$
\begin{aligned}
& \left.\mathrm{h}_{21}=\frac{\mathrm{Fr}_{\mathrm{r}}^{2}}{2}\left(\mathrm{n}^{2}-\frac{1}{3}\right)\left[\operatorname{Asin} 2 \mathrm{ks}+\mathrm{B}_{2} \cos 2 \mathrm{ks}+1\right)+2 \mathrm{C}_{3} \mathrm{e}^{-\mathrm{cs}} \cos \mathrm{ks}\right] \\
& \mathrm{h}_{22}=\frac{\mathrm{Fr}_{\mathrm{r}}^{2}}{2}\left[\mathrm{~J}_{1} \sin 2 \mathrm{ks}+\mathrm{J}_{2} \cos 2 \mathrm{ks}+\mathrm{J}_{3} \mathrm{e}^{-\mathrm{cs}} \sin \mathrm{ks}+\mathrm{J}_{4} \mathrm{e}^{-\mathrm{cs}} \cos \mathrm{ks}\right. \\
& \left.\quad+\mathrm{J}_{5} \mathrm{e}^{-\mathrm{cs}}+\mathrm{J}_{6}+\mathrm{J}_{7} \mathrm{e}^{-\mathrm{cs}}\right] \\
& \mathrm{u}_{2}(\mathrm{~s}, \mathrm{n})=\frac{\mathrm{ck}_{1}+2 \mathrm{kK}_{2}}{\mathrm{c}^{2}+4 \mathrm{k}^{2}} \sin 2 \mathrm{ks}+\frac{\mathrm{ck}_{1}-2 \mathrm{kK}_{2}}{\mathrm{c}^{2}+4 \mathrm{k}^{2}} \cos 2 \mathrm{ks}+\frac{\mathrm{K}_{4}}{\mathrm{k}} \mathrm{e}^{-\mathrm{cs}} \sin \mathrm{ks}
\end{aligned}
$$




$$
\begin{aligned}
& \frac{k_{3}}{k} e^{-c s} \cos k s-\frac{k_{5}}{c} e^{-c s}+\frac{K_{6}}{c-C_{2}} e^{-c_{2} s}+\frac{K_{7}}{c}+\left(n^{2}-\frac{1}{3}\right) u_{i 2} e^{c(s-s)} \\
& -e^{c\left(s_{0}-s\right)}\left[\frac{K_{1} c+2 k K_{2}}{c^{2}+4 k^{2}} \sin 2 k s_{0}+\frac{c K_{2}-2 k K_{1}}{c^{2}+4 k^{2}} \cos 2 k s_{\circ}+\right. \\
& \frac{K_{4}}{k} e^{-c s_{0}} \sin k s_{0}-\frac{K_{3}}{k} e^{-c s_{0}} \cos k s_{0}-\frac{K_{5}}{c} e^{-2 c s_{0}}+\frac{K_{6}}{c-c_{2}} e^{-c_{2} s_{0}}+\frac{K_{7}}{c} \\
& v_{2}=\left(1-n^{2}\right)\left(D \cos k s+E \sin k s+C_{4} e^{-C s}\right)
\end{aligned}
$$

where $\mathrm{B}_{2}=\mathrm{B}-1 / 2, \mathrm{~J}_{1}, \mathrm{~J}_{2}, \mathrm{~J}_{3}, \mathrm{~J}_{4}, \mathrm{~J}_{5}, \mathrm{~J}_{6}, \mathrm{~J}_{7}, \mathrm{~K}_{1}, \mathrm{~K}_{2}, \mathrm{~K}_{3}, \mathrm{~K}_{4}, \mathrm{~K}_{5}, \mathrm{~K}_{6}$ and $\mathrm{K}_{\mathrm{T}}$ are constants which we can not show thelr detailed expression due to the restriction on space. $h_{2}$ in Eq. 12 shows the deviation of the water surface from the sectional average one.

Through Eqs. 9 to 12 we reach the full expressions up to the second order solutions. The shear stress is determined by Eq. 2 .

\section{COMPARISON OF THE THEORY AND EXPERIMENTAL DATA}

3.1 Transverse Distribution of the Depth-Averaged Velocity

The geometry of the flume in our laboratry has been shown in previous paper (4). The coefficient expressing of the idealized bed topography in the $\mathrm{fifth}$ equation of Eq. 8 are as follows: $a_{0}=0.673, a_{1}=$ $3.110, a_{2}=7.357, a_{3}=3.708$ and $a_{2}=2.712$. Fig. 3 shows the comparison between the measured and the calculated values of the transverse depthaveraged velocity. The theortical transverse velocity distribution shows that the highest velocity which appears near the inner bank in the first half of the bend tends to shift towards the outer bank as the flow goes downstream. For our experimental data, unfortunately we don't have measured values near the inner bank at the area between section $\pi / 4$ and section $5 \pi / 12$ due to the shallowness of the water depth. It is seen from Fig. 3 that the theoretical values show a good agreement with the measured values in magnitude as well as the transverse profile. The

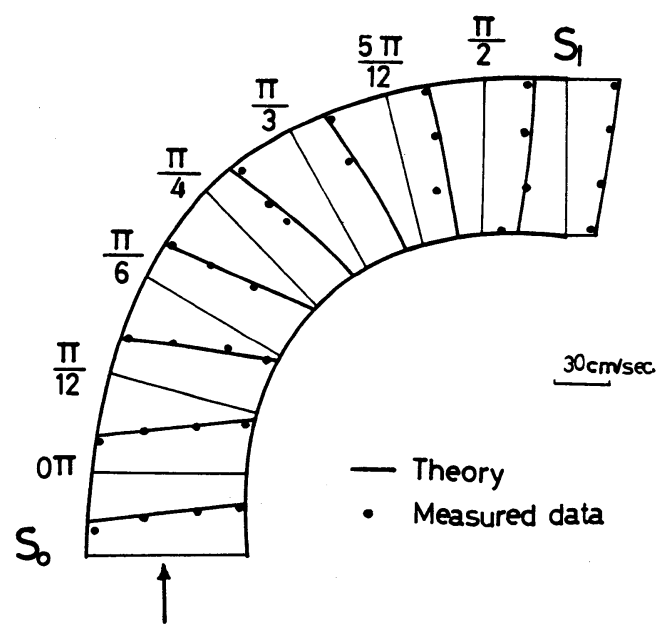

Fig. 3 Distribution of depth-averaged longitudinal velocity (second order) 


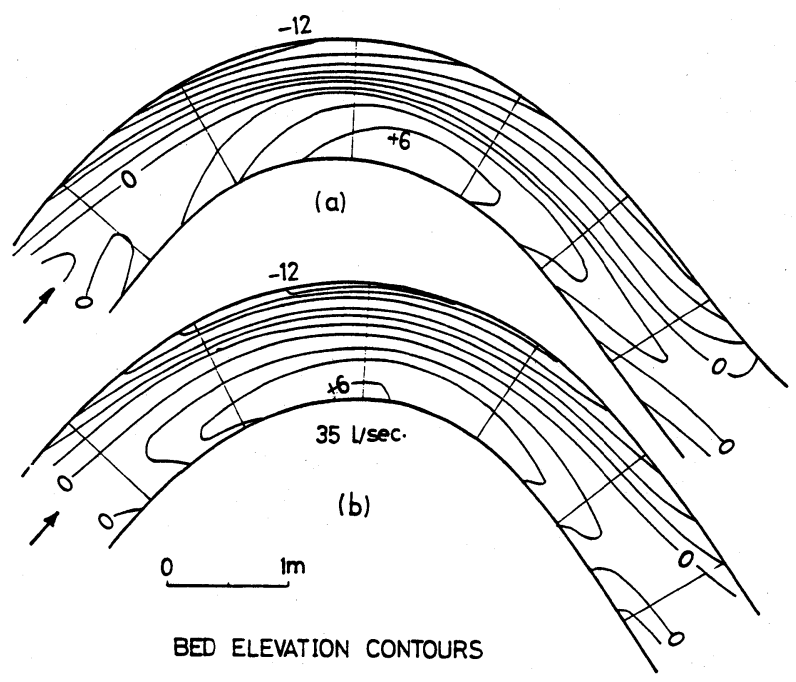

Fig. 4 Bed topography

(a) Measured by Hooke Run 35

(b) Simulated by Eq. (8) 5

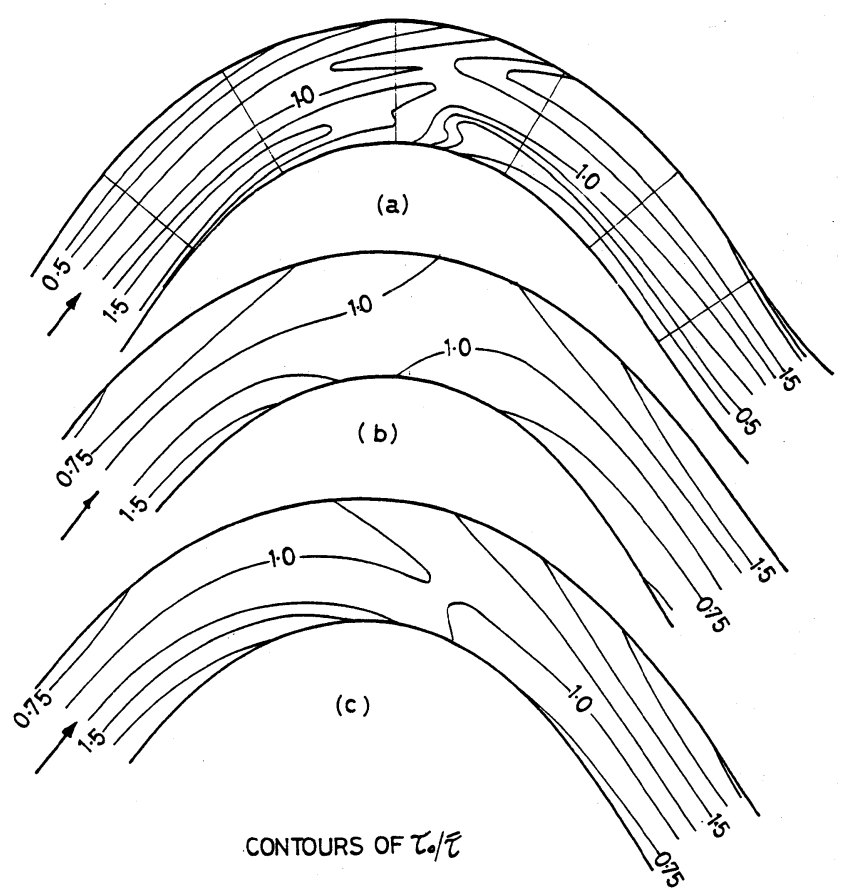

Fig. 5 Shear stress distribution

(a) Measured by Hooke Run 35

(b) Calculated (First order)

(C) Calculated (Second oreder) 
depth-averaged velocity distribution by the first order theory is linear for the transverse direction variation and the magnitude estimated by the first order theory seems satisfactory. The general behavior of the theoritcal resultsis also supported by other experimental data (5). At the point of appearance of the highest transverse velocity, the present theory differs from Engelund's (1) theory which shows that the highest velocity moves towards the outer bank withinfor the first half of the unit bend.

\subsection{Comparison with Hooke's Experiment}

The centerline geometry of Hooke's flume coincides with a sinegenerated curve ( 2 ). Now, to compare the bed shear distribution measured by Hooke and the theoretical values calculated by Eq. 2 , it is needed to deterimine an idealized bed topography in order to calculate the depthaveraged flow. As an example for the comparison, Hooke's run 35 has been considered. Fig. 4 shows the measured and the calculated bed topography. It is found out the constants in the $\mathrm{fifth}$ equation of Eq. 8 equal to $a_{0}=0.393, a_{1}=4.465, a_{2}=8.938, a_{3}=-0.827$ and $a_{4}=2.013$. The overall agreement is fairiy good for the comparison of shear stress.

The results of the first and the second order estimation of the shear stress and the measured one are shown in Fig. 5 . It is seen that essential distribution pattern is reproduced by both the first and the second order theory.

\section{CONCLUSIONS}

1. The theory shows good agreement with the variation of the measured depth-averaged flow velocity and bottom shear stress along meandering channels.

2. The contribution of the second order term in the theory does not seem to be substantial. However, for the detailed discussion more precise measurement is needed.

\section{REFERENCES}

1) Engelund, F."Flow and bed topography in channel bends", Proc. ASCE, vol. 100, Hy. 11, pp.1631-1647, 1974 .

2) Hooke, R.L." shear- stress and sediment distrebution in meander bend" UNGI-report 30 , Univ. of UpPsala, 58 p., 1974.

3) I keuchi, $K$ and N. Tamai "Evoulation of depth-averaged flow field in meandering channels, Proc. JSCE, No. 334, pp. 89-101, 1983 (in japanese).

4) Tamai, N. and Ali A. Mohamed"Velocity profiles in continuous bends over idealized bars" Annual meeting of JSCE, 1984.

5) Yen, C.L." Bed topography effect on flow in a meander" Proc. ASCE, vol. 96, No. Hy. 1, Pp. 57-73, 1970. 